\title{
تماسك جماعة العمل وعلاقته بمقاومة التغيير التنظيمي في المؤسسة الاقتصادية الجزائرية
}

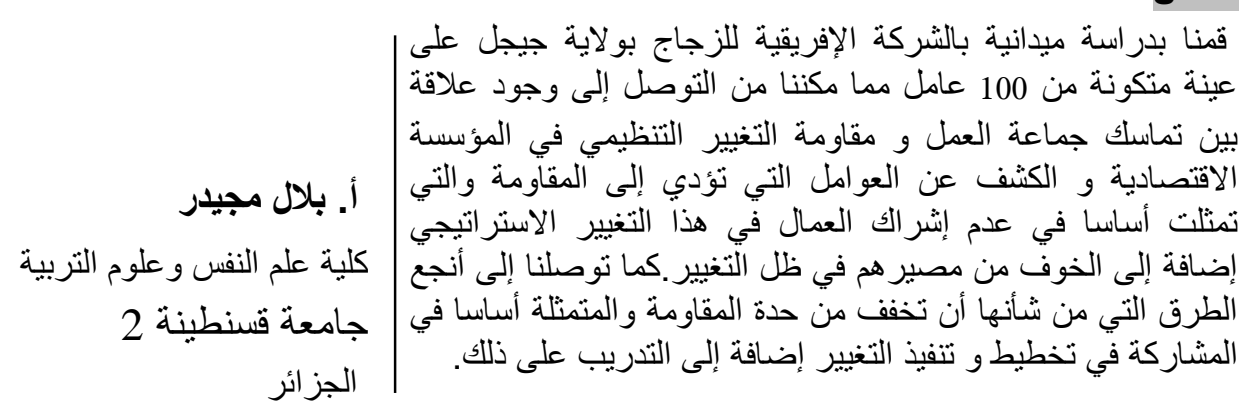

\section{مقدمة}

الإلهسان وبحكم أنه اجتماعي بطبعه فقد

شكل منذ القدم تتظيمات وجماعات بشرية ابتداء الإئه

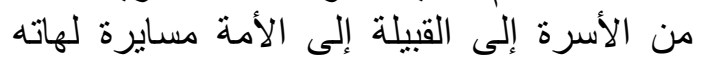

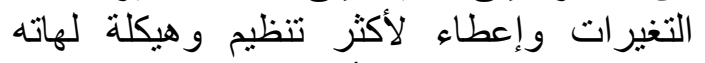

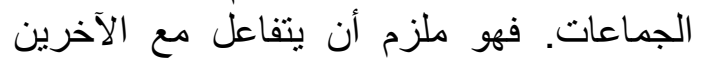

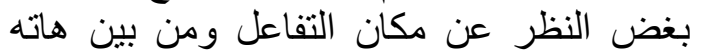

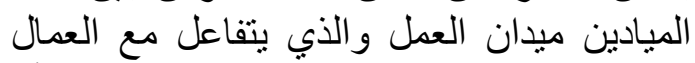

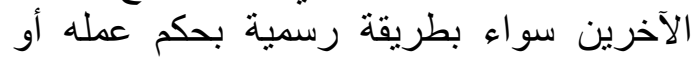
بطريقة غير رسمية من خلال مشاركته نفس رئة

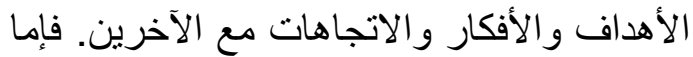
أن يكون هذا التفاعل إيجابي يزيد الإندات من قوة

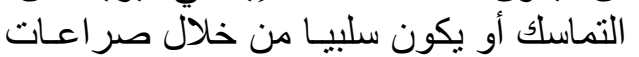

\section{Résumé}

Cette étude porte sur l'impact de la cohésion du groupe au travail sur la résistance au changement chez eux L'échantillon de recherche est composé de 100 travailleurs. L'outil de recherche est construit à travers deux questionnaire : l'un sur la cohésion du groupe et l'autre sur la résistance au changement.

$$
\text { تكون انعكاساتها سلبية على روحه المعنوية و على أدائه وعلى المنظمة ككل . }
$$


وكما ذكرنا سابقا التغير شيء يحدث في حياتنا اليومية و يتجلى من حولنا في صور

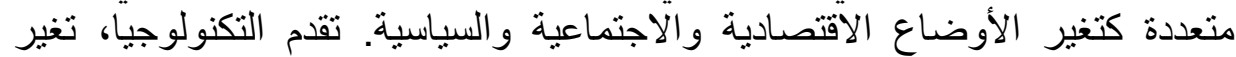

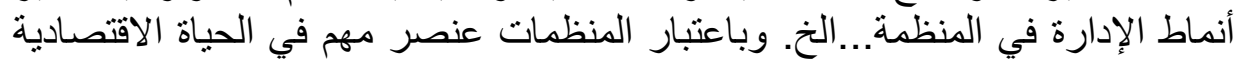

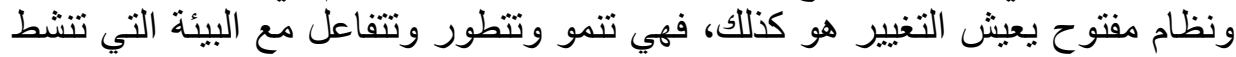
فيها. فالتغيير ظاهرة طبيعية تقتضي تغير تلتير تلك المنظمات وتكيفها ومسايرة هاتها

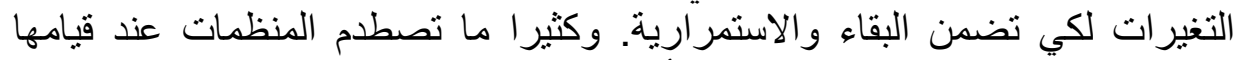

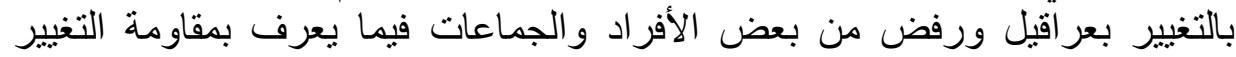

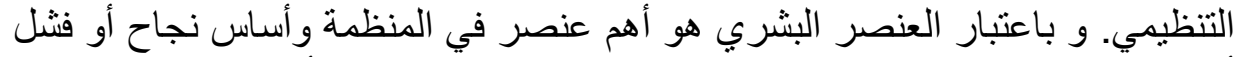
أي عملية تغيير فكثير ا ما لعبت جماعات العمل سواء رسمية الوفية أو غير رسية رسية دورا

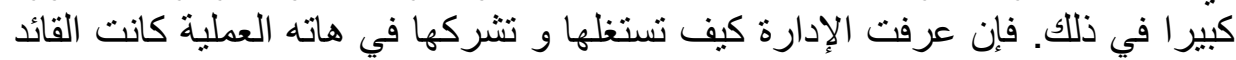

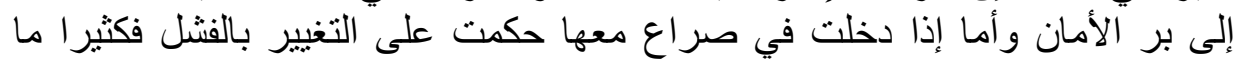
تقاوم الجماعات عملية التغيير ككتلة واحدة بكل الطرق الإفتشالها.

ومن خلال هاته الدراسة سنحاول الكثف عن العلاقة الموجودة بيت تماسك جماعة

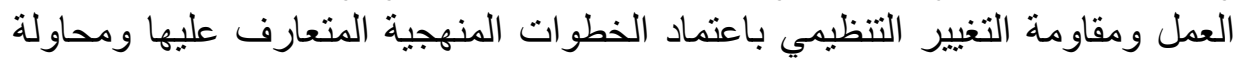

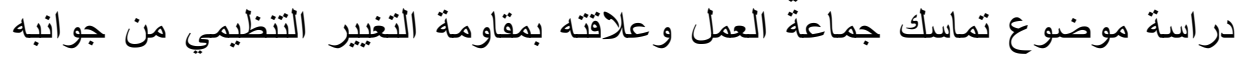

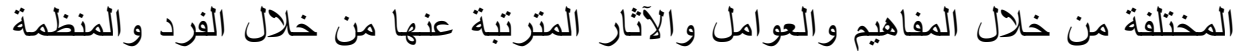

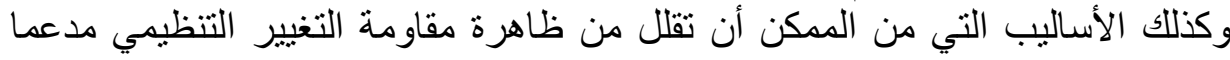

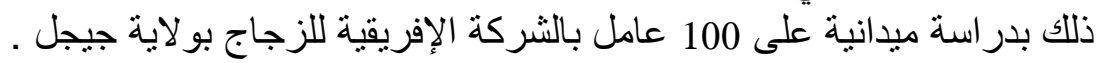

أولا : الإطار المفاهيمي للاراسة :

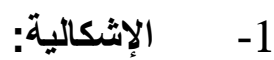

من طبيعة العلوم الدينامكية و التغير فهو بحاجة إلى التقدم و التطور في كل مجالات

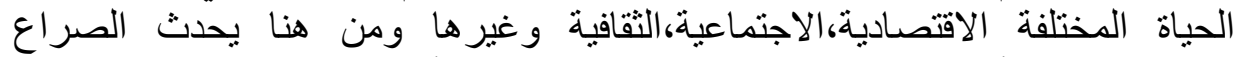

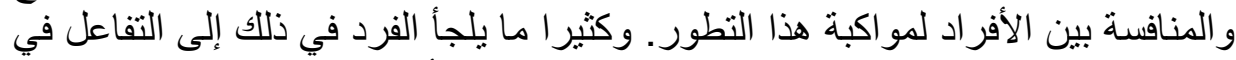

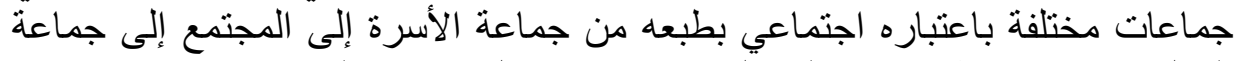

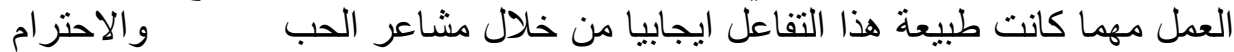

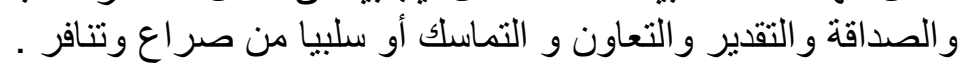

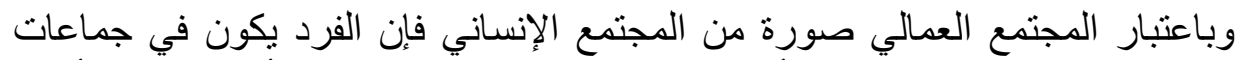

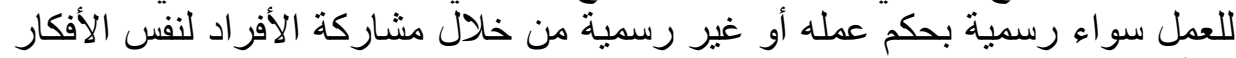

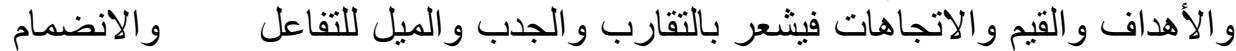

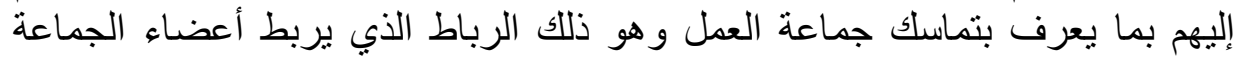

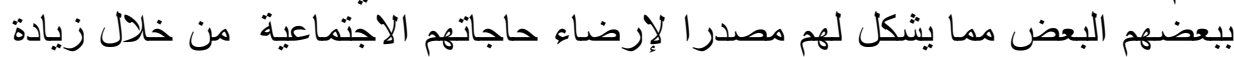

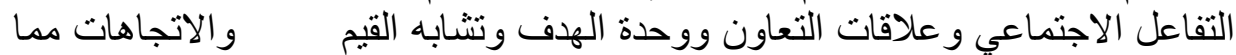


يجعلها صدا منيعا للتصدي للمخاطر الخارجية ويزيد من درجة الولاء للجماعة وكل ما يتعلق بها .

وكثير ا ما كان لتماسك جماعة العمل آثار ايجابية على الفرد والمنظمة من خلال الراء

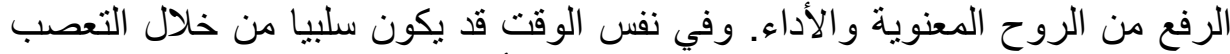

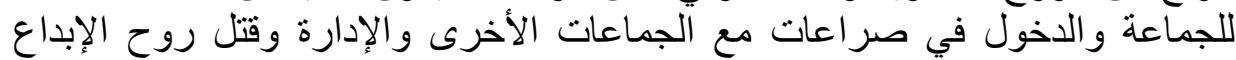

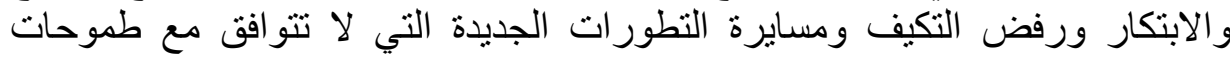
الجماعة حتى ولو كانت جيدة.

و المنظمة وباعتبار ها ميدانا لهاته الجماعات فهي صورة عاكسة لحقيقة انعكاسات تماسك جماعة العمل بإيجابياتها و سلبياتها ومن أهم المظاهر التنظيمية التي تتجلى فيهاتيا

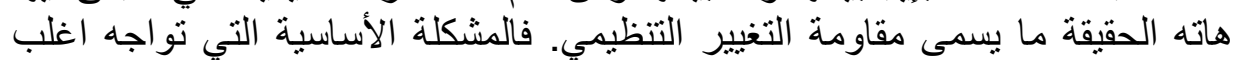

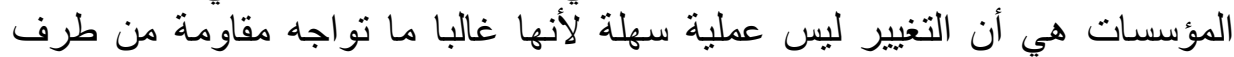

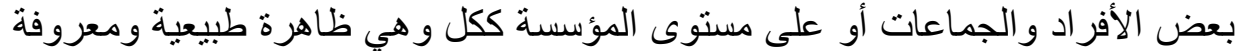

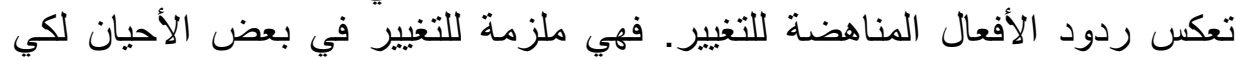

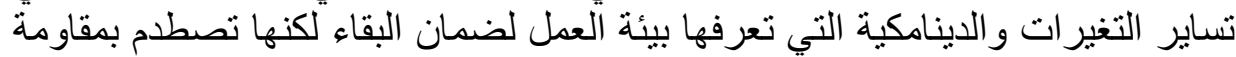

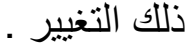

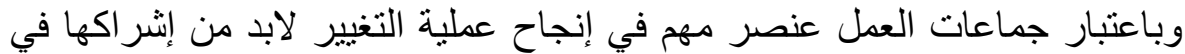

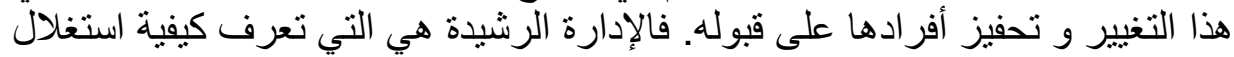

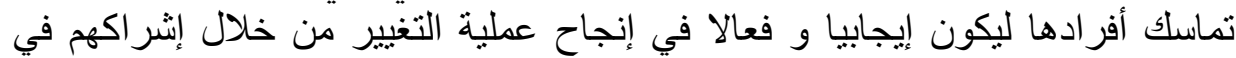

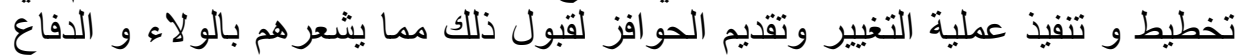

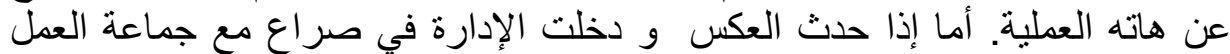

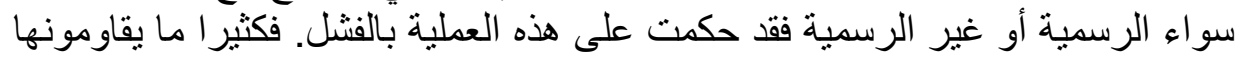

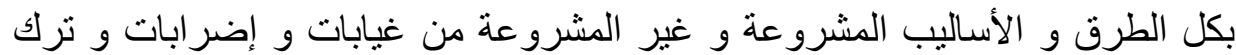

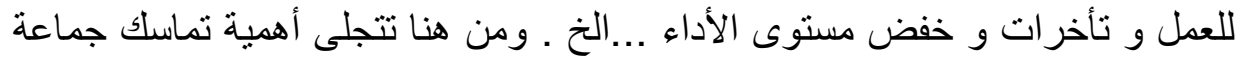
العمل في إنجاح أو فثل عملية التغيير التنظيمي . و هو ما يدفعنا لطرح التساؤلات البحثية التالية :

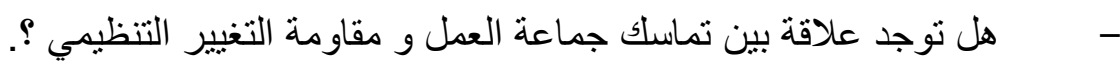

$$
\text { 2- }
$$

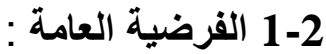

هناك علاقة ذات دلالة إحصائية عند مستوى الدلالة \05،0 بين تماسك جماعة

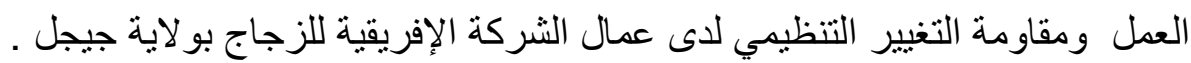




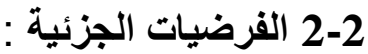

1- هناك علاقة ذات دلالة إحصائية عند مستوى الدلالة >05،0 بين التفاعل الاجتماعي بين أعضاء جماعة العمل ومقاومة التغيير التنظيمي لاى الاى عمال الثركة الإفريقية

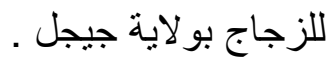

2- هناك علاقة ذات دلالة إحصائية عند مستوى الدلالة \05،05 بين وجود العلاقات التعاونية بين أعضاء جماعة العمل ومقاومة التغات التيير التنظيمي لدى عمال الثركة

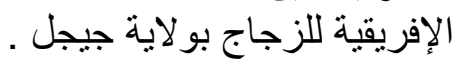

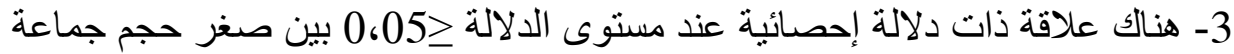

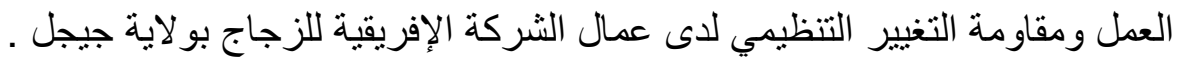

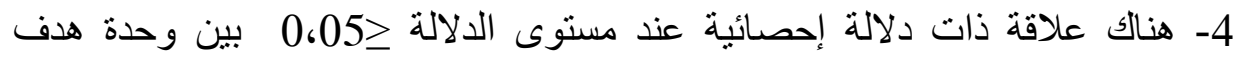

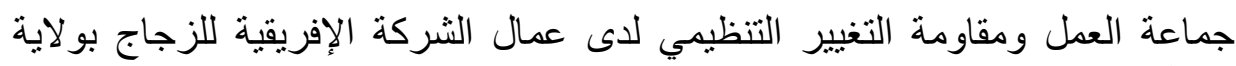

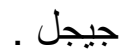

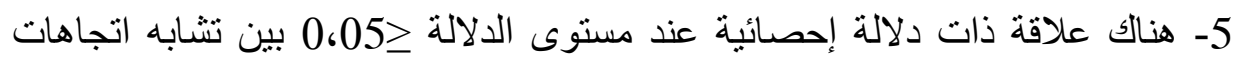

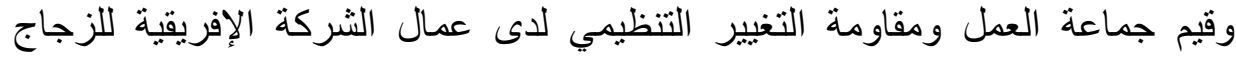

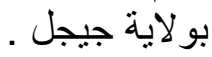

6- هنالك علاقة ذات دلالة إحصائية عند مستوى الدلالة >05، بئن بين وجود تهيدات خارجية على جماعة العمل ومقاومة التغيير التنظيمي لدى عمال الثال الثركة الإفريقية

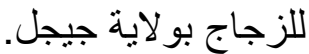

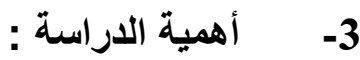

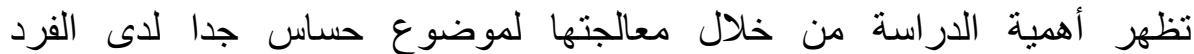

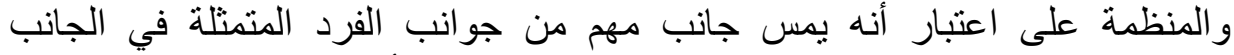

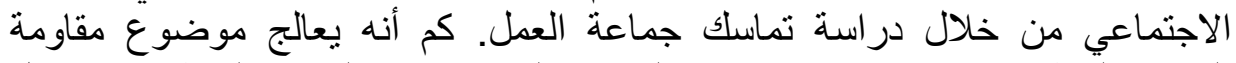

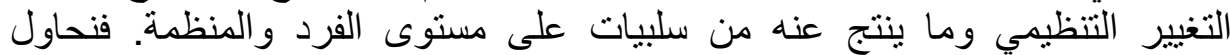

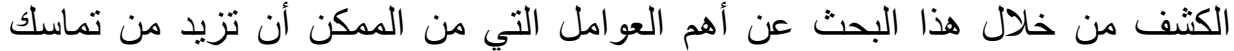

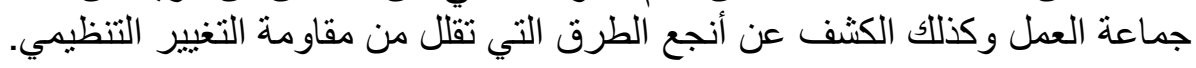
- إمكانية التعرف ميدانيا على واقع تماسك جماعة العمل و علاقته بمقاومة التغيير 
ـ الوصول إلى بعض النتائج التي من الممكن أن تساعد على إعطاء بعض الاقتراحات التي من الممكن المؤسسات الاستفادة منها في التقليل من مقاومة التهن التغيير التنظيمي.

4- أهداف الاراسة :

- تسليط الضوء على ماهية تماسك جماعة العمل و مقاومة التغيير التنظيمي . ـ محاولة معرفة العلاقة الموجودة بين تماسك جماعة العمل ومقاومة التغيير التنظيمي. ـ معرفة العو امل التي من الممكن أن تزيد من تماسك جماعة العمل ومن مقاومة التغيير التنظيمي. ـ الكثف عن أنجع الطرق والأساليب التي من الممكن أن تقلل من مقاومة التغيير

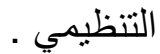

\section{5- 5 - 5نهج الدراسة :}

من خلال ما سبق و على ضو اء الفرضيات تم اعتماد المنهج الوصفي التحليلي وهو

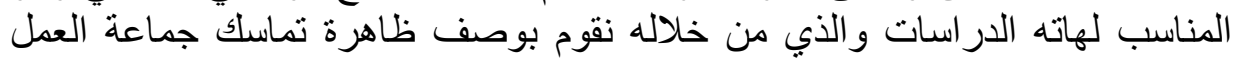

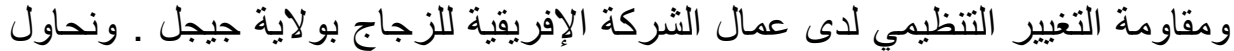

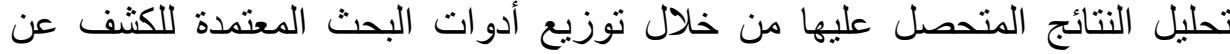
العلاقة الموجودة بين متغير ات البحث.

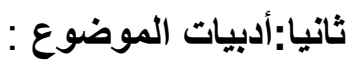
أولا : تماسك جماعة العمل : 1 - مفهوم تماسك الجماعة:

يقصد بلفظ التماسك مقدار المشاعر الإيجابية التي يكنها أعضاء الجماعة لبعضهح

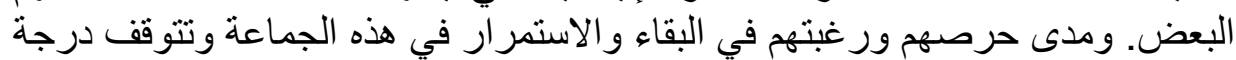
تماسك الجماعة على قوة الجذب التي تتمتع بها الجماعة لإبقاء أعضائها داخلها ولتها وعدم انسحابهم منها.

وبطبيعة الحال تختلف درجة التماسك والتعاون بين أعضائها ففي بعض الجضاء الجماعات

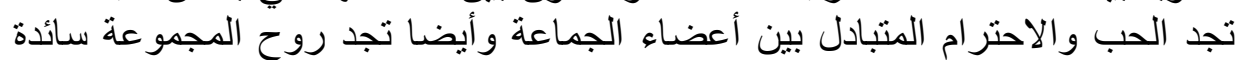

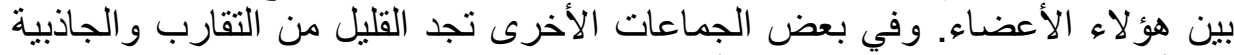

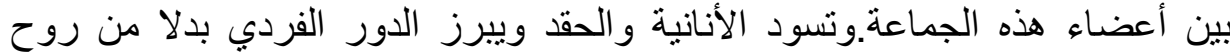

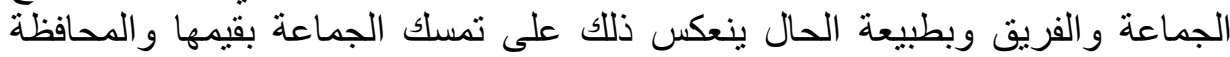

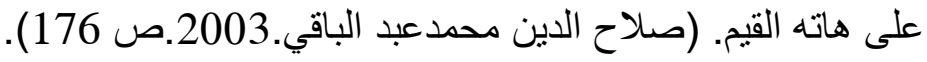




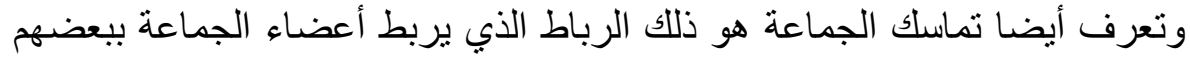

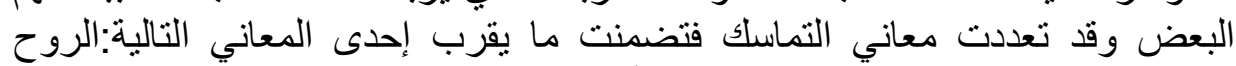

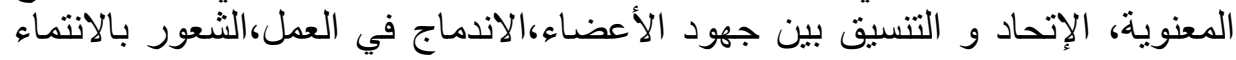

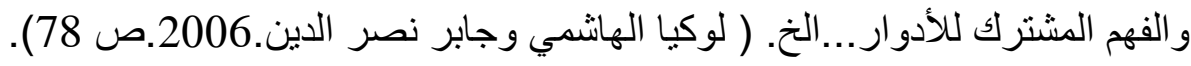

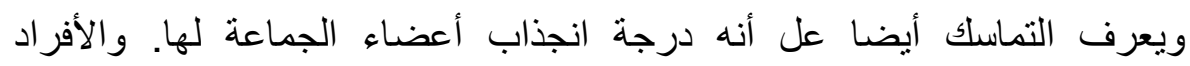

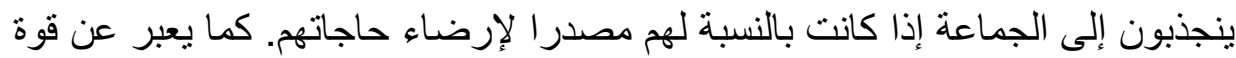

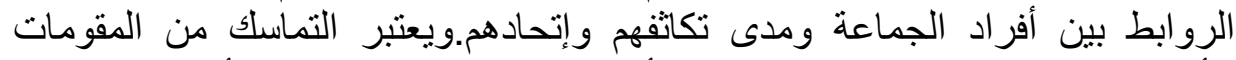

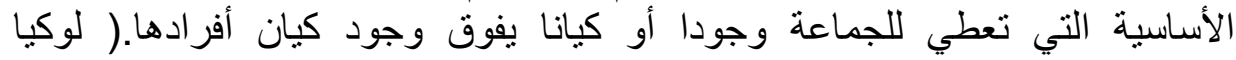

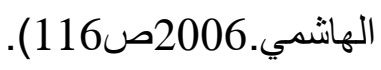

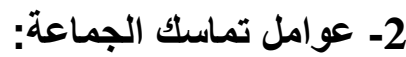

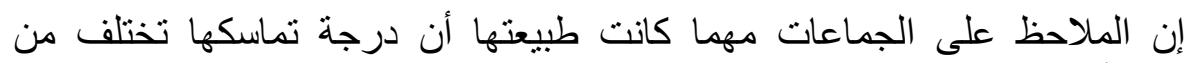

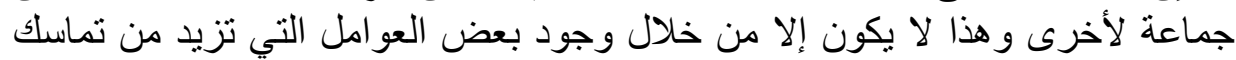

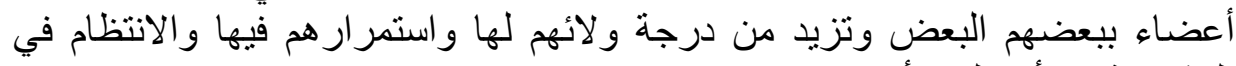
المشاركة في أعمالها و أهدافها.

1-2 درجة التفاعل بين أعضاء الجماعة:

من أهم المصادر الرئيسية والعوامل المؤدية لتماسك الجماعة ووحدتها هو مقدار

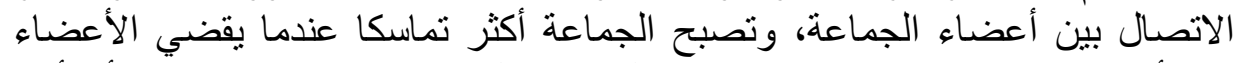

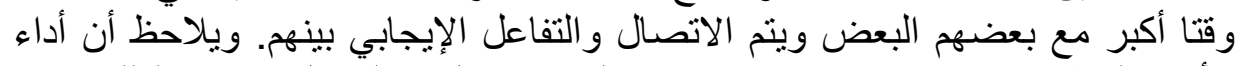

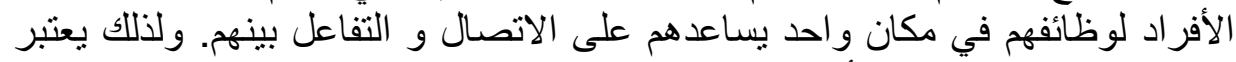

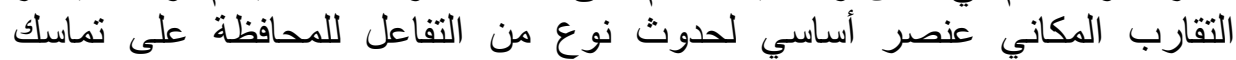

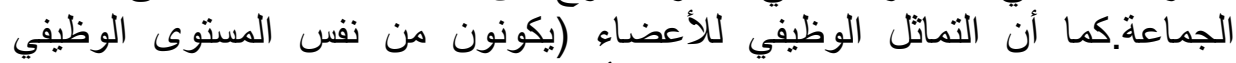

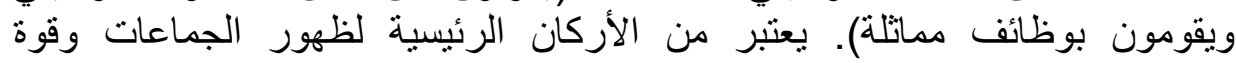

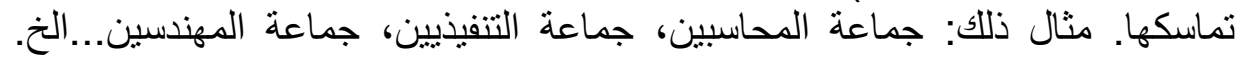

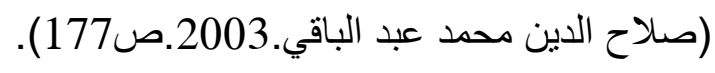

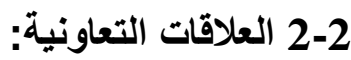

تؤدي العلاقات التعاونية إلى تماسك الجماعة وزيادة جاذبيتها فيصعب ألى أن تقوم

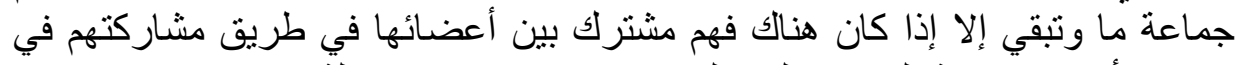
تحديد الأهداف و إقامة المعايير التي يلتزمون بنان فها في حدود معقولة. 
وفي تجربة قام بهاDeutsch دويتش وجد أن الجماعات التعاونية أظهرت الكثير

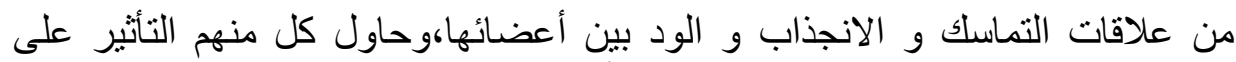

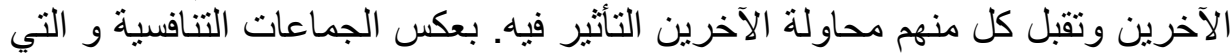

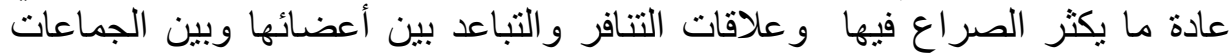

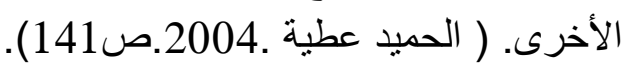

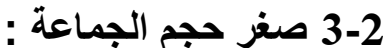

يقال أن هناك علاقة عكسية بين حجم الجماعة ودرجة تماسكها فكلما كانت الجماعة

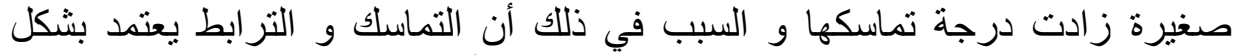

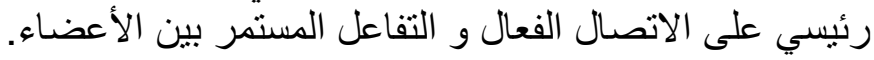

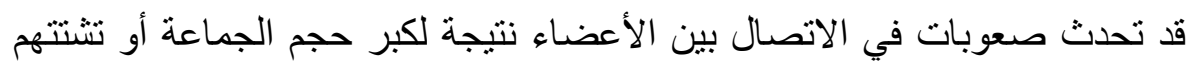

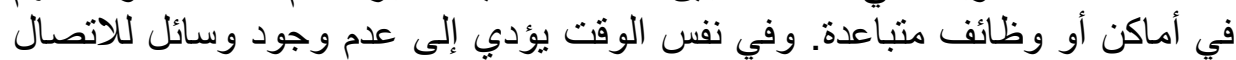

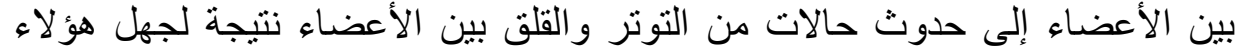

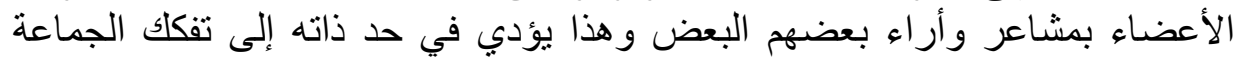
و وعدم تماسكها.

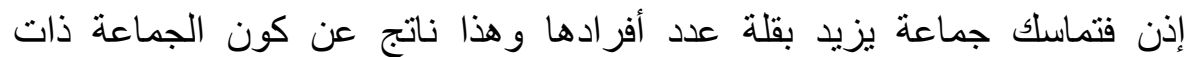

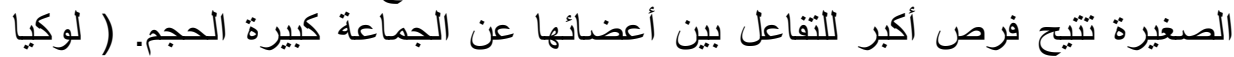

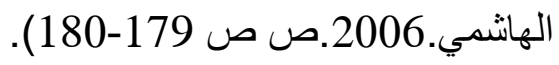

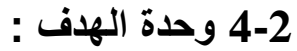

فالجماعات التي تتكون لتحقيق أهداف مشتركة لأعضاء الجماعة تصبح أكثر

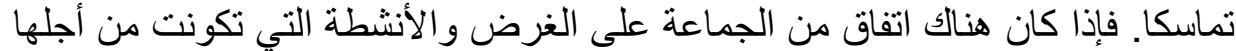

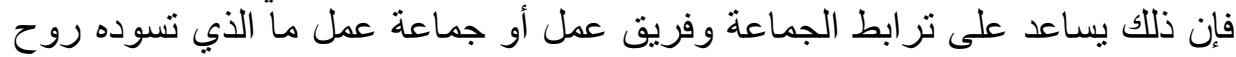

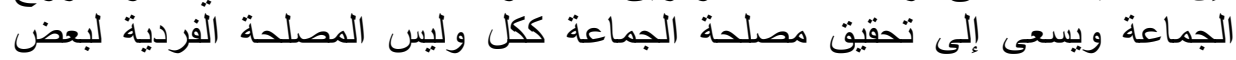

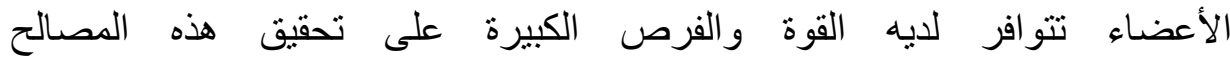

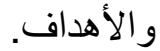

و ون ناحية أخرى فان قدرة الجماعة على تحقيق أهدافها ينعكس على درجة تماسكها

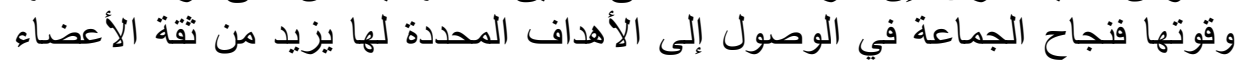

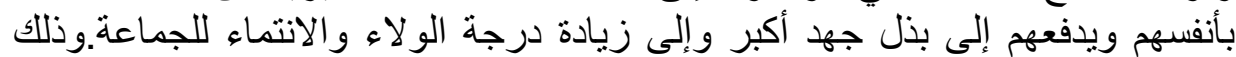

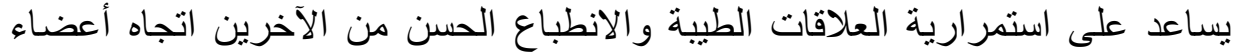

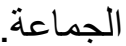


5-2 وحدة اتجاهات وقيم الجماعة:

من أقوى مصادر تماسك الجماعة هو تثنابه الاتجاهات والقيم لأعضاء الجماعة الأباء

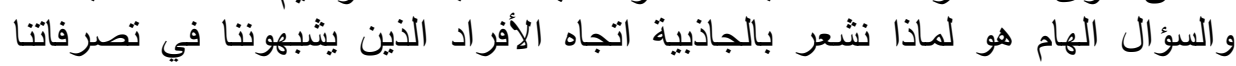
وآر ائنا و عقائدنا؟

$$
\text { وبطبيعة الحال هناك أسباب ور اء ذلك ومن أهمها: }
$$

أن الثخص الذي يشاركنا نفس الآراء يمدنا بنوع من التأييد الاجتماعي لمعتقداتنا

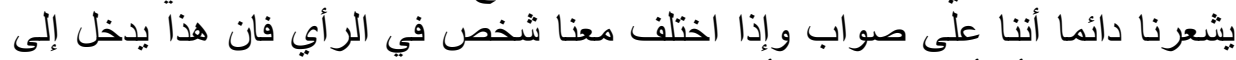

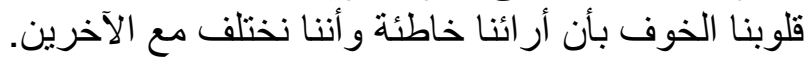

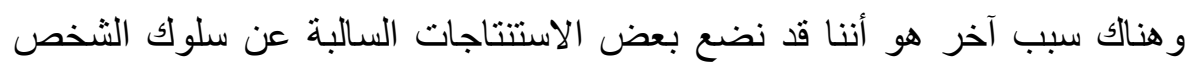

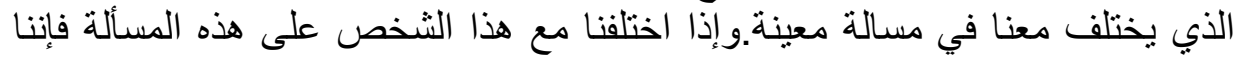

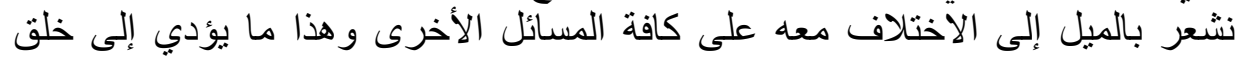

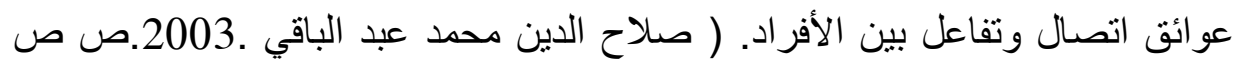

.(179-178

\section{6-2 التصدي للتهديدات الخارجية:}

إن زيادة التماسك بين جماعة العمل ترتبط أحيانا كثيرة بحدة الضغوط و التهديدات

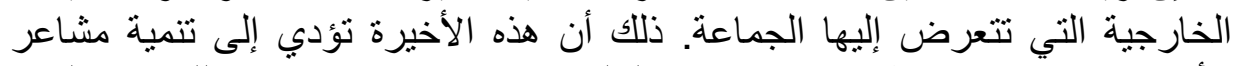

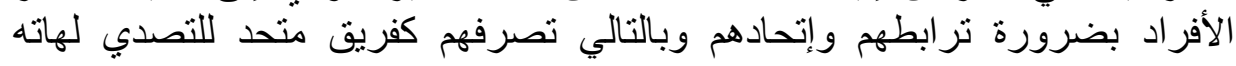

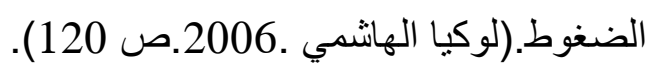

3 - عوامل إضعاف تماسك الجماعة:

1-3 الاختلاف حول الأهداف: مثلما يؤدي الاتفاق حول هدف ومسار المجموعة إلى الى تلاحم الجماعات يؤدي الاختلاف إلى الصراع والعراك الك ويضعف درجة الأف تماسك الجماعة.

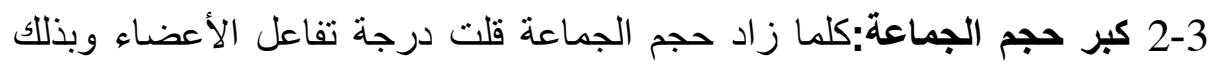

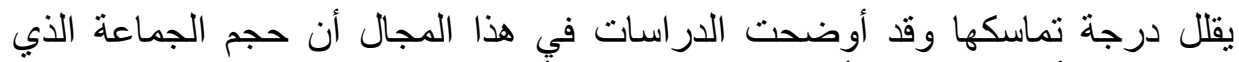

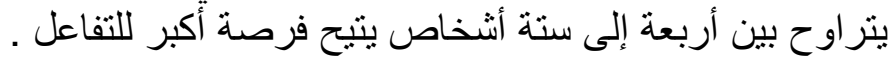
3-3 التجارب الغير سارة في الجماعة:حينما ينعدم التقارب و التقة بين أعضاء الجماعة

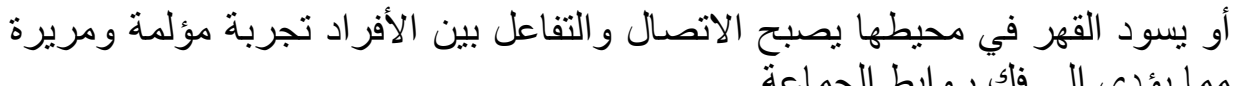


4-3 التنافس داخل الجماعة:مع أن التنافس بين الجماعات يؤدي إلى التقارب بينهما

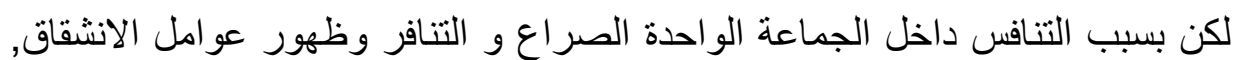

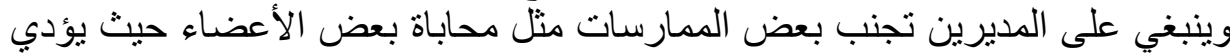
ذللك إلى وجود التنافس الغير بناء بين أفراد الجماعة و الذي يخلق الصراع الاع و التنافر. 5-3 السيطرة: حينما يسيطر واحد أو أكثر على الجماعة أو يتجهون نحو عدم التفاعل

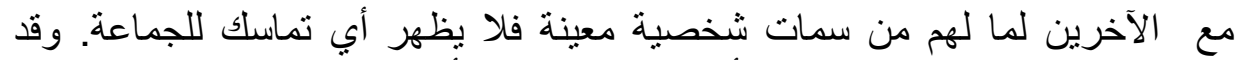

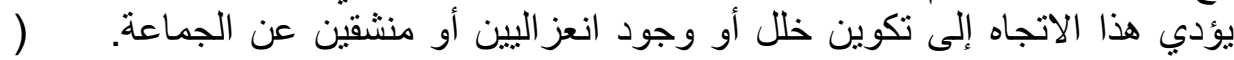
أندرو سيز لاقي. 1991.ص الاتجاه البك 223). 4- - الآثار الإيجابية لتماسك الجماعة: ويلخص لوثا نز نتائج تماسك الجماعة على مستوى الفرد و على مستوى المنظمة كما يلي: 1-4 التأثير على فعالية الفرد: - تلبية حاجات القبول و الانتماء. ـ ـ مساعدة الفرد على معرفة ذاته وما يتعلق بالمنظمة. - المساعدة في اكتساب مهار ات جديدة. ـ ـ الحصول على عو ائد قيمة لا يمكن الحصول عليها منفردا. ـ تحقيق أكبر قدر ممكن من الرضا وبالتالي الإنتاجية. 2-4 التأثير على فعالية المنظمة: - إنجاز الأعمال التي لا يمكن أداؤها من قبل الأفر اد أنفسهم. ـ استقطاب المواهب و المهار ات لمعالجة مشكلات صعبة. ـ ـتنكل أداة لصنع القرار ات مما يتيح ظهور أراء عديدة. ـ ـ تسهيل عملية تغيير سياسات وإجر اءات المنظمة . ـ تزيد من استقرار المنظمة عن طريق تقبل القيم و المعتقات المشتركة للعاملين.

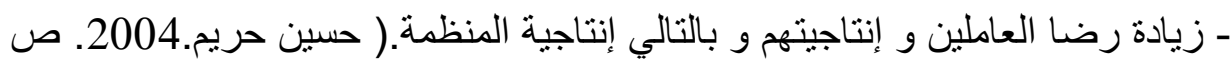




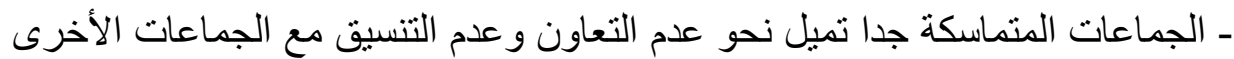

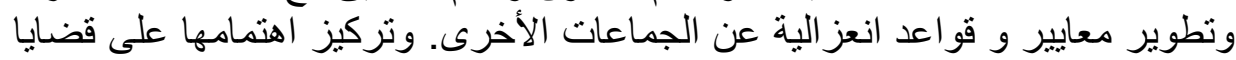

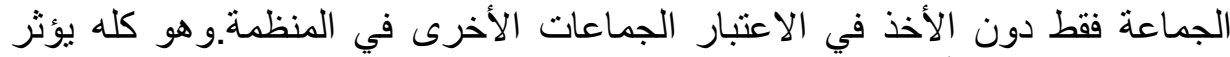
سلبا على مستوى الأداء في المنظمة. ـ قتنل روح الإبداع والابتكار .

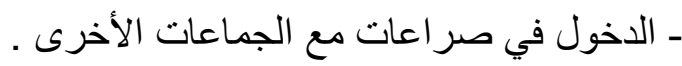
- عدم قبول ومقاومة كل ما لا يتو افق مع أهداف الجماعة و طموحاتها حتى و ولو لو كان جيد و والتعصب للجماعة. ـ مقاومة كل تغيير أو تطوير و اعتباره خطر وتهديدا للجماعة. ثانيا: مقاومة التغيير التنظيمي. 1 - تعريف مقاومة التغيير التنظيمي:

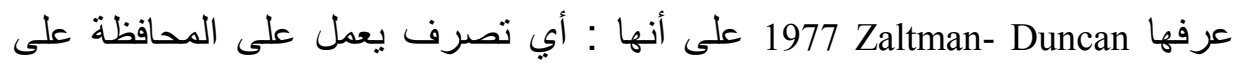

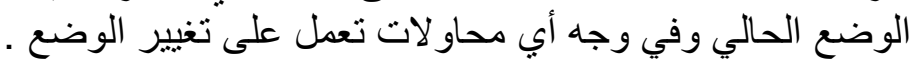

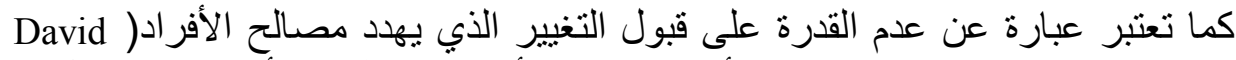

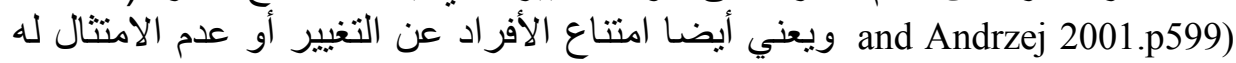

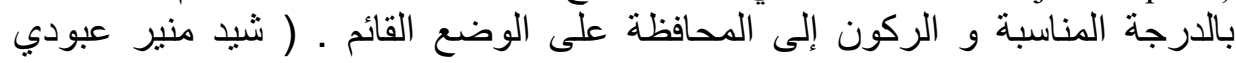

$$
\text { 2007. بـ 200. }
$$

وبصفة عامة مقاومة التغيير التنظيمي هي شكل من أشكال رفض التغيير المزعم القيام

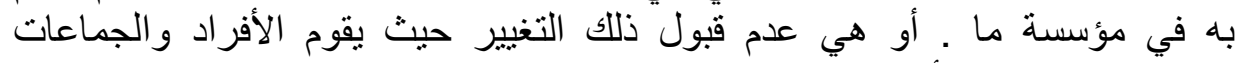

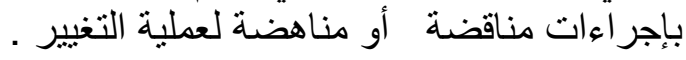

\section{2- أسباب مقاومة التغيير التنظيمي :}

1-2 الأسباب النفسية: و تتمثل في الشعور بعدم الأمان و الخوف من الخطر في هذا

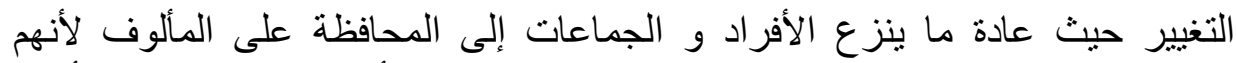

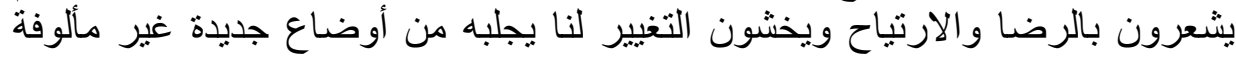

ومعروفة. Brown and harvey.2006)

2-2 الأسباب التنظيمية: بمكن تلخيص الأسباب التنظيمية فيما يلي : 
ـالفنتل في السابق في عملية التغيير: تخاف المنظمات من أي تغيير لفتشاها في تجارب

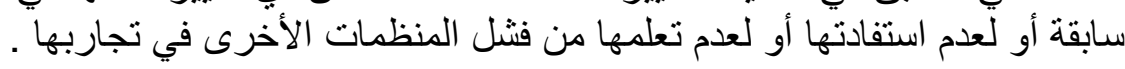
- الغرور بالنجاح العالي : حيث تقاوم بعض المنظمات بسبب غرورها من نجاح

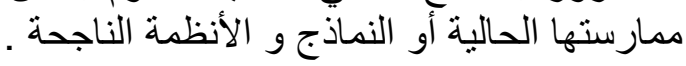
- عدم التأكد من نتائج التغيير: تفضل بعض المنظمات عدم الخده الخوض في التغيير

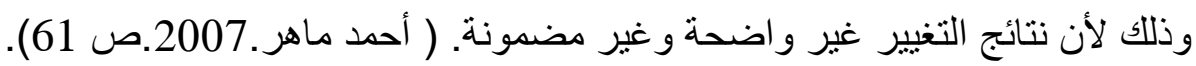

3-2 الأسباب الاقتصادية :كثيرا من العمال يرون أن عملية التغيير تهديدا لمركز هم

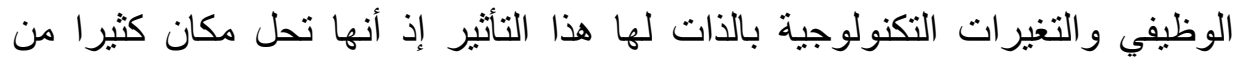

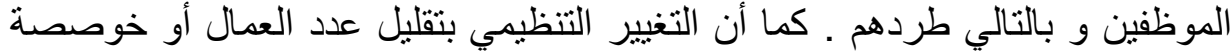

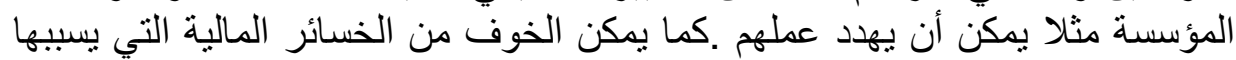

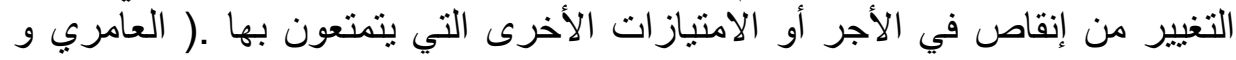

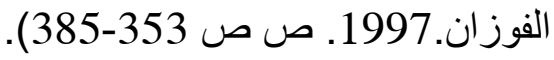

3- سلبيات مقاومة التغيير التنظيمي :

من أهم سلبيات مقاومة التغيير التنظيمي ما يلي: ـ انخفاض الروح المعنوية للعمال الر افضين للتغبير التنظيمي . - إعاقة التكيف والقدرة على تحقيق الأهداف و إنجاز المهام التنظيمية. - ظهور سلوكات تنظيمية سلبية من غياب ودوران العمل وخفض الإن الأداء

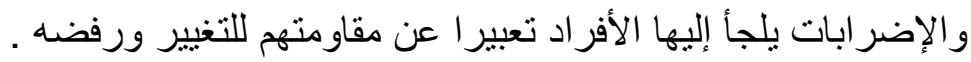

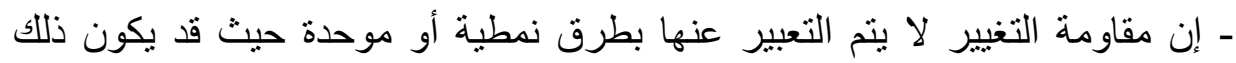

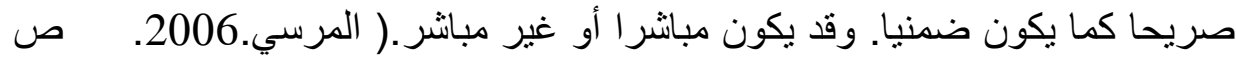

- عندما تكون نتائج التغيير إيجابية و انعكاساتها على الموظف و المنظمة سلبية مقارنة

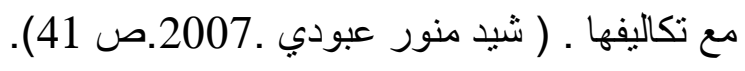

4- إيجابيات مقاومة التغيير التنظيمي : قد لا تكون مقاومة التغيير التنظيمي سلبية دائما قد تكون إيجابية في بعض الأحيان فقد

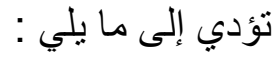


-جعل القائمين على عملية التغيير التنظيمي أكثر دقة واستعدادا وتهيئة له . - توضيح أهداف و أسباب و أهمية التغيير للعاملين بهدف عدم مقاومته عند التطبيق.

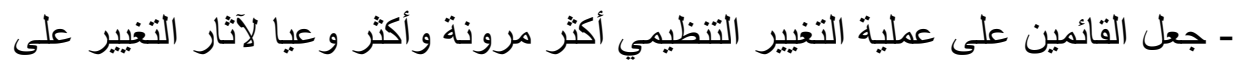
العاملين على المدى القريب و البعيد. - توفير الفرصة للعاملين للتعبير عن مشاعر هم و أفكار هم عن التغيير . - تساعد على اكتشاف نقاط القوة والضعف في العمل وفي حالة معالجة المشكلات واتخاذ القرارات.

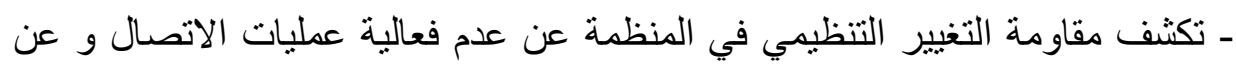

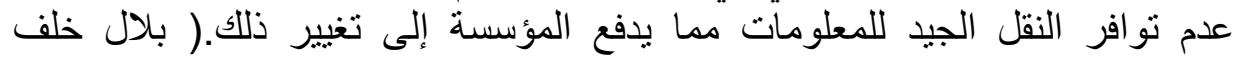

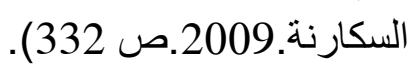

\section{5- أساليب مقاومة التغيير التنظيمي :}

يعبر الأفراد و الجماعات عن مقاومتهم و رفضهم للتغيير التنظيمي بطريقة صريحة أو مأو

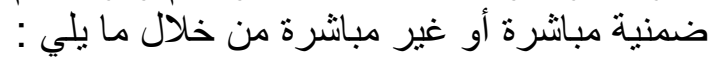

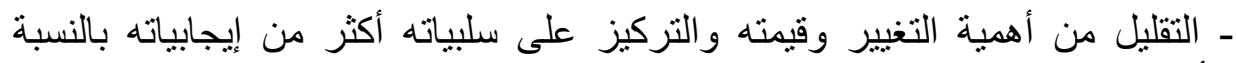
للأفر ادو و المنظمة. ـ التشكيك في قدرة المسؤولين على إنجاح التغيير والدخول في صر اعات مع قادة التغيير. ـ التحجج بعدم القدرة و التدريب الكافي للقيام بعملية التغيير. ـ القيام بإضر ابات رفضا لعملية التغيير و التحجج بغموض عملية التغيير .

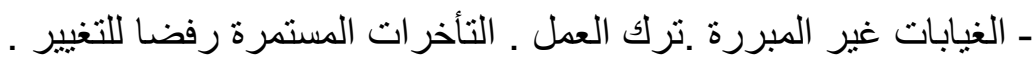

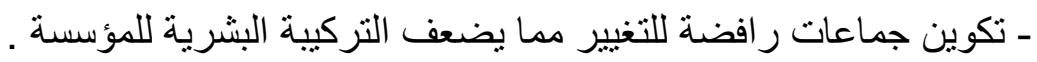

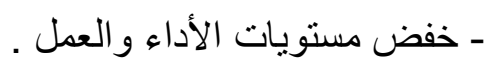

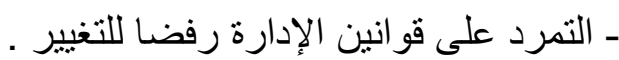

\section{6- إستراتيجيات التقليل من مقاومة التغيير التنظيمي :}

ـ التعليم و الاتصال: و هو إعلام ومناقثنة التغيير مع العاملين. ـ المشاركة : و هو مشاركة الأفر اد في تخطيط وتصميم و تنفيذ عملية التغيير .

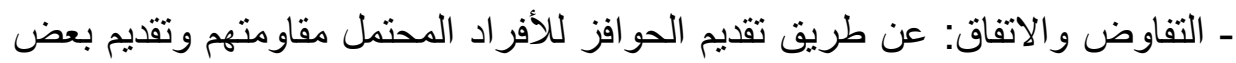

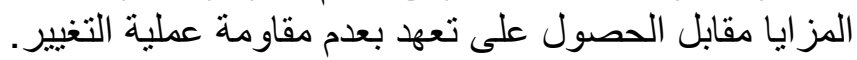

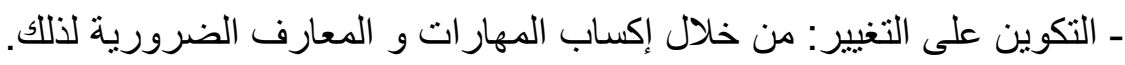


ـ الإكراه الصريح: وهو استخدام القوة لجعل الأفراد يتقبلون التغيير.(جيري ل جيري

1988.ص656

\section{7- مقاومة التغيير التنظيمي و جماعة العمل :}

تكون جماعة العمل سلاح ذو حدين فإن الإدارة الرشيدة هي التي تعرف كيف

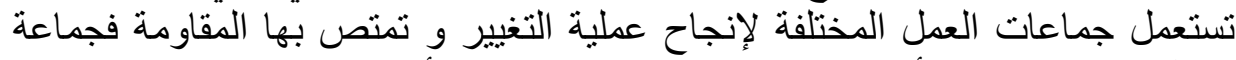

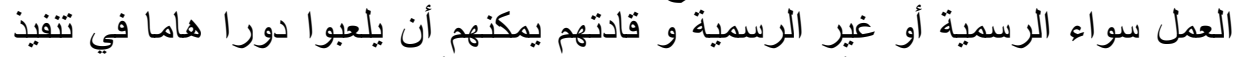
عملية التغيير ذلك بسبب تأثثرهم على الجماعات فإذا أستطاع المشرفون على الثى عملية

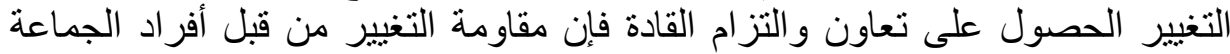

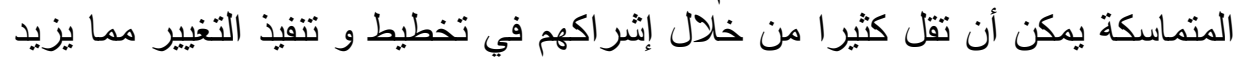

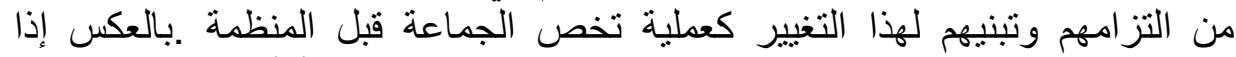

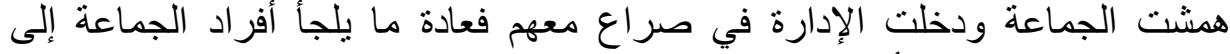

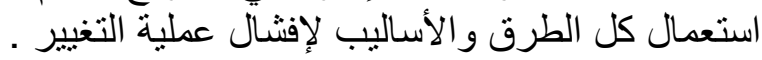

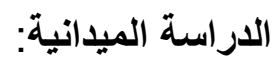

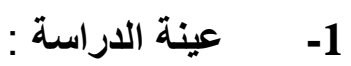

شملت العينة 100 عامل من مختلف المستويات الوظيفية بالثركة الإفريقية للزجاج

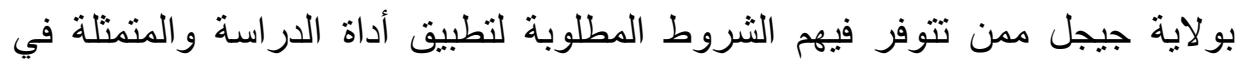
الاستبيان المصدم من طرف الباحثة ـ. و التي تم اختيار هم بطريقة عشوائية بسيطة

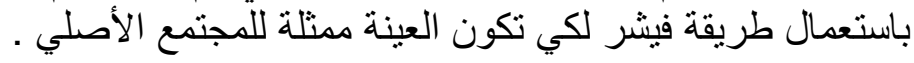

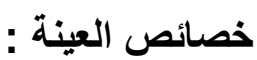
1-1 السن : جدول رقم (01) يبين توزيع أفر اد العينة حسب السن :

\begin{tabular}{|c|c|c|}
\hline النسبة المئوية & التكرار & الفئة \\
\hline$\% 18$ & 18 & $(28-18)$ \\
\hline$\% 28$ & 28 & $(39-29)$ \\
\hline$\% 33$ & 33 & $(50-40)$ \\
\hline$\% 21$ & 21 & أكثر من 50 سنة \\
\hline$\% 100$ & 100 & المجموع \\
\hline
\end{tabular}

من خلال الجدول رقم(01) نلاحظ أن أفراد العينة أغلبهم كهول وكبار في السن ما بين (40-50) سنة ب33\% و أكثر من 50 سنة ب21\% بينما فئة الثباب ما بين (18-28) 
سنة ب18 \% و (29-39) ب 28\% وهذا يدل على أن المؤسسة مزيج بين الثباب و الكهول و هو مؤشر جيد للحالة العمرية للمؤسسة . 2-1 الجنس : جدول رقم (02) يبين توزيع أفر اد العينة حسب الجنس :

\begin{tabular}{|c|c|c|}
\hline النسبة المئوية & التكر ار & الفئة \\
\hline$\% 90$ & 90 & ذكر \\
\hline$\% 10$ & 10 & أنتى \\
\hline$\% 100$ & 100 & المجموع \\
\hline
\end{tabular}

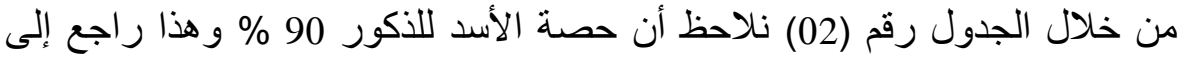

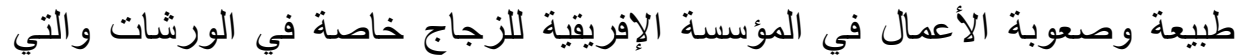

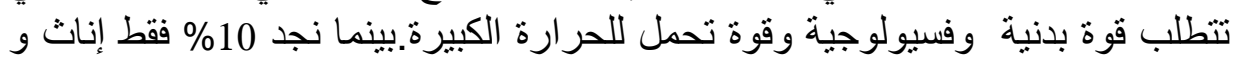
يشغلون ووظائف إدارية. 3-1 الوضعية الاجتماعية: جدول رقم(03) يبيت توزيع أفراد العينة حسب الوضعية

\begin{tabular}{|c|c|c|}
\hline النسبة المئوية & التكرار & الفئة \\
\hline$\% 32$ & 32 & أعزب \\
\hline$\% 65$ & 65 & متزوج \\
\hline$\% 03$ & 03 & مطلق \\
\hline$\% 00$ & 00 & أرمل \\
\hline$\% 100$ & 100 & المجموع \\
\hline
\end{tabular}

من خلال الجدول رقم (03) نلاحظ أن 65 \% من أفراد العينة متزوجون بينما 32 \% عز اب و 03 \% مطلق و هذا يساعد كثير ا على الاستقر ار و التفاني في العمل. 4-1 المستوى الوظيفي: جدول رقم(04) يبين توزيع أفراد العينة حسب المستوى

\begin{tabular}{|c|c|c|}
\hline النسبة المئوية & التكرار & الفئة \\
\hline$\% 39$ & 39 & تنفيذ \\
\hline$\% 32$ & 32 & تحكم \\
\hline$\% 29$ & 29 & إطار \\
\hline$\% 100$ & 100 & المجموع \\
\hline
\end{tabular}


من خلال الجدول رقم (04) نلاحظ أن أغلبية أفراد العينة من عمال التنفيذ 39 \% نظر الخصوصية الثركة المتمثلة في الإنتاج داخل ورشات العمل.بينما 32 \% تحكم هم رؤساء الفرق و المصالح و29 \% إطار ات في المؤسسة.

\begin{tabular}{|c|c|c|}
\hline النسبة المئوية & التكر ار & الفئة \\
\hline$\% 06$ & 06 & ابتدائي \\
\hline$\% 36$ & 36 & متوسط \\
\hline$\% 35$ & 35 & ثانوي \\
\hline$\% 23$ & 23 & جامعي \\
\hline$\% 100$ & 100 & المجموع \\
\hline
\end{tabular}

نلاحظ من خلال الجدول رقم (05) أن أغلبية أفراد العينة لديهم مستوى تعليمي منتسط و ثانوي 71 \% و هذا نظرا لطبيعة الوظائف التي بشغلونها والتي لا تتطلب مستوى تعليمي بل بعض القدرات البدنية والفسيولوجية. بينما 23 \% جامعي يشغلون مناصب إدارية و إطار ات في المؤسسة. حين نجد 06 \% ابتدائي يشغلون مناصب

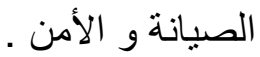

6-1 الخبرة المهنية : جدول رقم(06) يبين توزيع الأفر اد حسب الخبرة المهنية :

\begin{tabular}{|c|c|c|}
\hline النسبة المئوية & التكر ار & الفئة \\
\hline 39 & 39 & $(5-0)$ \\
\hline 09 & 09 & $(10-6)$ \\
\hline 00 & 00 & $(15-11)$ \\
\hline 52 & 52 & أكثر من 15 سنة \\
\hline 100 & 100 & المجموع \\
\hline
\end{tabular}


نلاحظ من خلال الجدول رقم (06) أن أغلبية أفراد العينة لايهم أكثر من 15 سنة خبرة بنسبة 52 \% و هذا دليل على استقرار المؤسسة على مستوى اليد العاملة إضافة

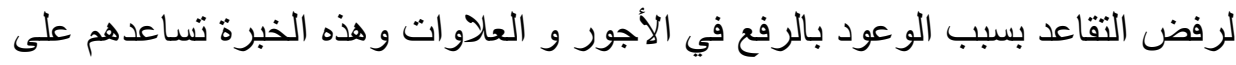

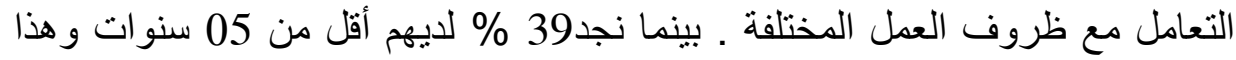
نظر السياسة التشبيب التي بدأت المؤسسة في تطبيقها في السنوات الأخيرة. 2- 2 أدوات جمع البيانات :

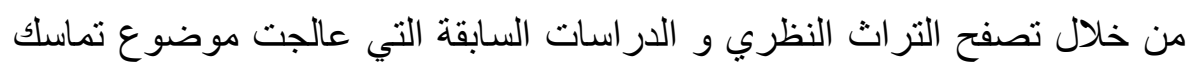

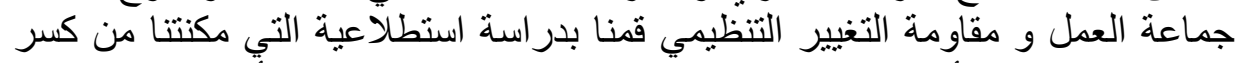

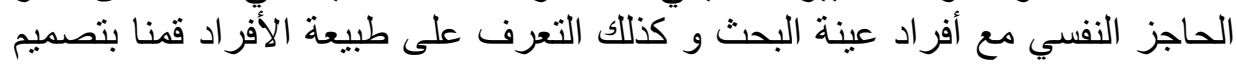

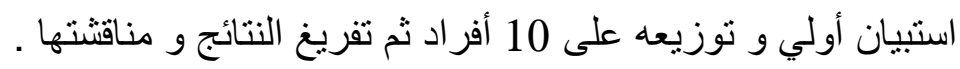
1-2 الاستبيان: بعد الدراسة الاستطلاعية قمنا بتصميم استبيان يقيس تماسك جماعة العمل وآخر يقيس مقاومة التغيير التنظيمي. ولدر اسة صدقه تم عرضه على التى 08 أساتذة

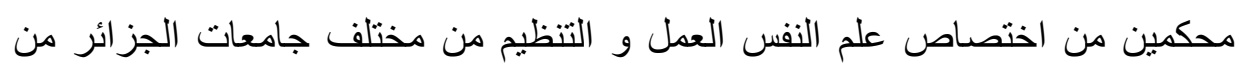

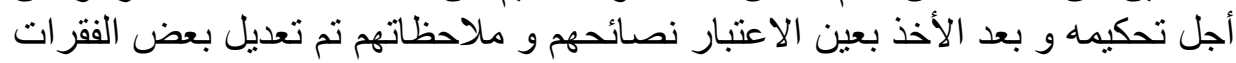
و إعادة صياغة الاستبيان في صورته الاخدين النهائية كما يلي : - استبيان تماسك جماعة العمل مكون من 72 بند مقسم إلى 06 محاور كل محور يشمل 12 بند من 1-12 يقيس التفاعل الاجتماعي.13-24 يقيس العمل الجماعي. 2536 يقيس صغر حجم الجماعة.37-48 يقيس وحدة الهدف.49-60 يقيس وحدة القيم. 72-61 يقيس التصدي للمخاطر الخارجية .

- استبيان يقيس مقاومة التغيير التنظيمي يتكون من 35 بند فيه مؤشرات مقاومة التغيير التنظيمي. 2-2 الثبات : قمنا بدر اسة ثبات الاستبيان باستعمال معامل ألفا قرونباخ حسب الجدول التالي :

\begin{tabular}{|c|c|}
\hline التفاعل الاجتماعي & المحاور \\
\hline 0.80 & العمل الجماعي الفا كرونباخ : \\
\hline 0.77 & 420 \\
\hline
\end{tabular}




\begin{tabular}{|c|c|}
\hline 0.68 & صغر حجم الجماعة \\
\hline 0.70 & وحدة الهذف \\
\hline 0.73 & وحدة القيم \\
\hline 0.70 & التصدي للمخاطر الخارجية \\
\hline 0.92 & تماسك جماعة العمل \\
\hline 0.97 & مقاومة التغيير التنظيمي \\
\hline
\end{tabular}

جدول رقم (07) يبين معاملات الثبات ألفا كرونباخ .

من خلال الجدول رقم (07) نلاحظ معدلات الثبات ألفا كرونباخ مرتفعة جدا وهذا مؤشر على ثبات الاستبيان سو اء على مستوى المحاور أو على المستوى الكلي . 3 - الأدوات الإحصائية المستعملة في تحليل النتائج :

1-3 معامل الارتباط : لقد تم استعمال معامل الارتباط بيرسون لحساب العلاقة بين تماسك جماعة العمل و مقاومة التغيير التتظيمي . 2-3 النسب المئوية: لحساب تمثيل المتغيرات الثخصية المتعلقة بأفر اد عينة البحث و

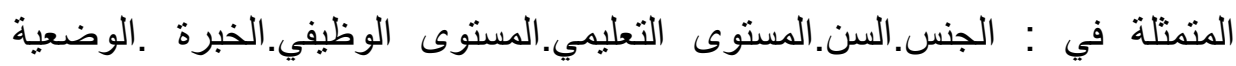
الاجتماعية.

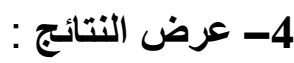

جدول رقم(08) يبين معاملا ت الارتباط بيرسون بين تماسك جماعة العمل ومقاومة

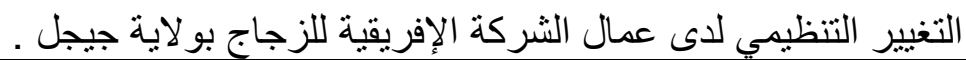

\begin{tabular}{|c|c|}
\hline معامل الارتباط بيرسون & العلاقة \\
\hline 0.024 & بين التفاعل الاجتماعي و مقاومة التغيير التنظيمي \\
\hline 0.033 & بين العمل الجماعي و مقاومة التغيير التنظيمي \\
\hline 0.047 & بين صغر حجم الجماعة و مقاومة التغيير التنظيمي \\
\hline
\end{tabular}


بلال مجيدر

\begin{tabular}{|c|c|}
\hline 0.027 & بين و حدة الهدف و مقاومة التغيير التنظيمي \\
\hline 0.021 & بين وحدة القيم و مقاومة التغيير التنظيمي \\
\hline 0.025 & بين التصدي للمخاطر الخارجية و مقاومة التغيير التنظيمي \\
\hline 0.006 & بين تماسك جماعة العمل و مقاومة التغيير التنظيمي \\
\hline
\end{tabular}

من خلال الجدول رقم (08) نلاحظ أن :

ـ معامل الارتباط بين التفاعل الاجتماعي و مقاومة التغيير التنظيمي هو 0.024 وهو دال عند مستوى الدلالة \05060 و بالتالي الفرضية الأولى تحققت و القائلة بأن هنالك

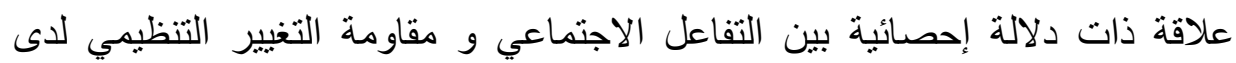

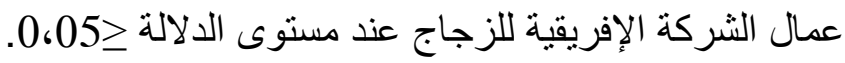
- معامل الارتباط بين العمل الجماعي ومقاومة التغيير التنظيمي هو 0.033 وهو دال عند مستوى الدلالة >05060 وبالتالي الفرضية الثانية تحققت و القائلة بأن هناك علاقة ذات دلالة إحصائية بين العمل الجماعي و مقاومة التغيير التنظيمي لدى عمال الثركة

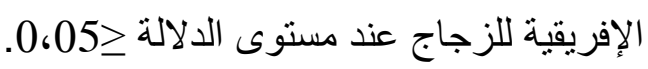
ـ معامل الارتباط بين صغر حجم الجماعة ومقاومة التغيير التنظيمي هو 0.047 وهو

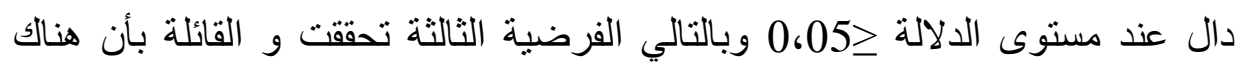

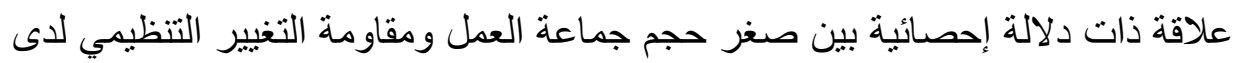

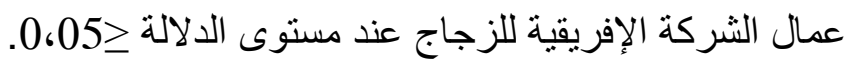
ـ معامل الارتباط بين وحدة الهدف و مقاومة التغيير التنظيمي هو 0.027 وهو دال عند مستوى الدلالة >05060 وبالتالي الفرضية الرابعة تحققت والقائلة بأن هناك علاقة ذات دلالة إحصائية بين وحدة الهدف و مقاومة التغيير التنظيمي لدى عمال الثركة التركة

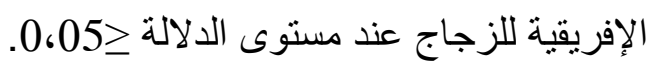
- معامل الارتباط بين وحدة القيم و مقاومة التغيير التنظيمي هو 0.021 و هو دال عند

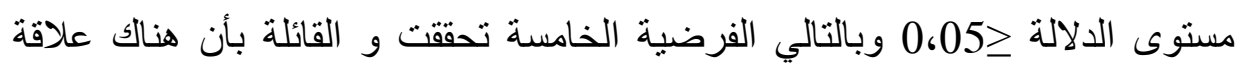
ذات دلالة إحصائية بين وحدة القيم و مقاومة التغيير التنظيمي لدى عمال الثركة

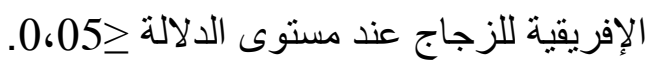


ـ معامل الارتباط بين التصدي للمخاطر الخارجية و مقاومة التغيير التنظيمي هو 0.025 و هو دال عند مستوى الدلالة \050605 و بالتالي الفرضية السادسة تحققت

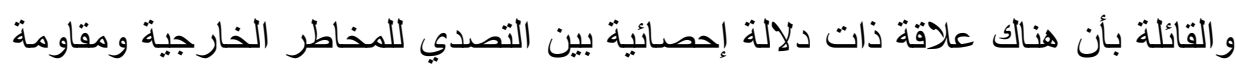

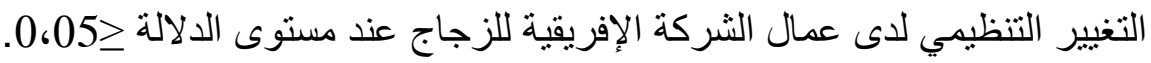
ـ معامل الارتباط بين تماسك جماعة العمل ومقاومة التغيير التنظيمي هو 0.006 وهو دال عند مستوى الدلالة \05060 و بالتالي الفرضية العامة تحققت والقائلة بأن هنالك علاقة ذات دلالة إحصائية بين تماسك جماعة العمل ومقاومة التغيير التنظيمي لدى بلى بلان

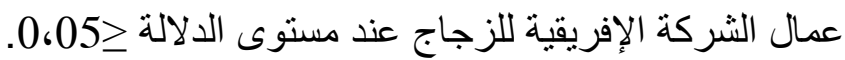

الخاتمة

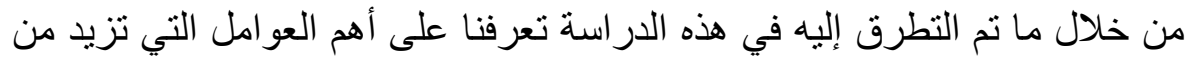

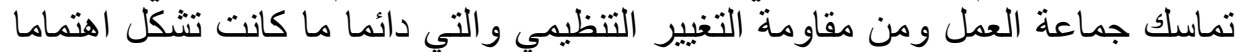

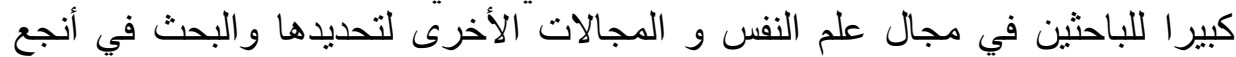

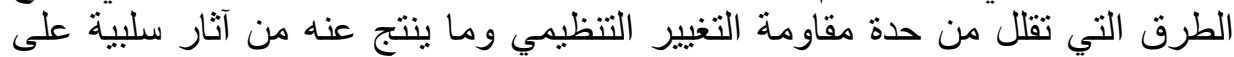

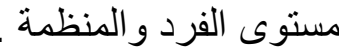

ولقد حاولنا أن نصل إلى نتائج موضو عية يمكن الوثوق بها وذلك من خلال استغلال

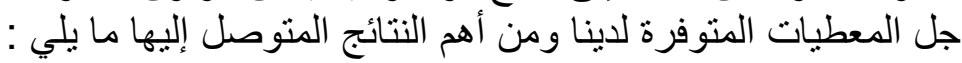

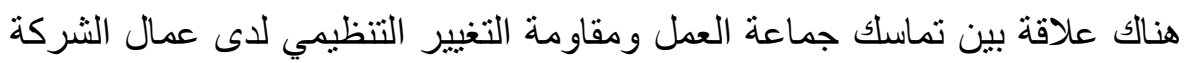
الإفريقية للزجاج بولاية جيجل من خلال معامل الارتباط بيرسون 0.006 وهو دال عند مستوى الدلالة ج 0.05. كما أن كل الفرضيات الجزئية تحققت . وكذلك توصلنا إلى بعض العو امل و الأسباب التي زادت من مقاومة العمال للتغيير

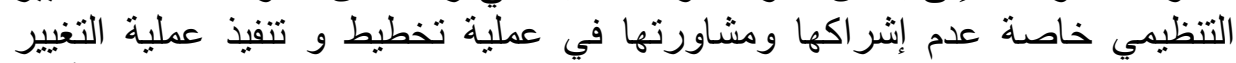

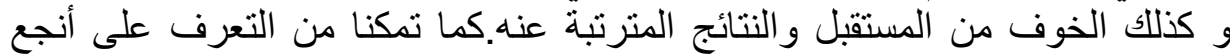
الطرق التي من خلالها يمكن أن نقلل من حدة مقاومة التغيير من خلال التها الإشر الك في

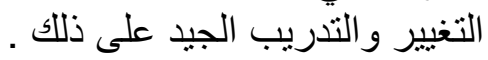
توصيات و مقترحات: ت ـالمساهمة في توطيد العلاقة بين أفراد الجماعات سواء الرسمية الرهات أو غير الرسمية من أجل زيادة تماسكها مما ينعكس إيجابيا على الفرد و والمنظمة. 
ـ تدريب قيادة فعالة على التغيير من أجل إنجاحه ومعرفة سبل التعامل مع ظاهرة

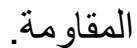
- إشر اك جماعة العمل في تخطيطو ت تنفيذ عمليات التغيير .

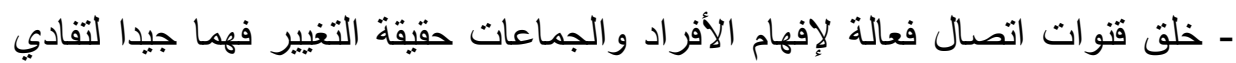

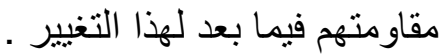

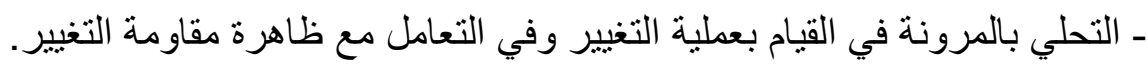
- عقد لقاءات ومناقثات ومحاضرات بين جميع عناصر عملية التغيير لثرح عملية التغيير. - توسيع مجال البحوث حول المصادر و العوامل التي تزيد من مظاهر مقاومة التغيير و البحث عن أنجع الطرق و الأساليب التي من الممكن أن تقلل من ذللك.

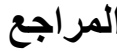

1- أحمد صقر عانشور .السلوك الإنساني في المنظمات.الدار الجامعية.لبنان.1989.

2- أحمد ماهر،تطور المنظمات الدليل العلمي لإعادة الهيكلة و التميز الإداري و إدارة

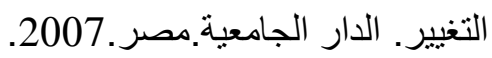

3- أندرو سيزلاقي.ترجمة جعفر أبو القاسم أحمد.السلوك التنظيمي والأداء. معهد الإدارة

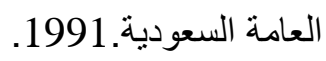
4-بركات حمزة حسين.علم النفس و ديناميات الجماعة.الدار الدولية.مصر.2008.

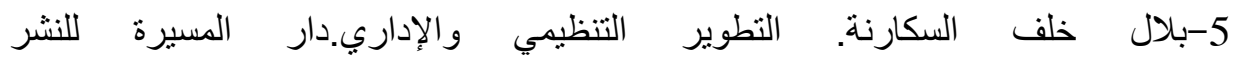

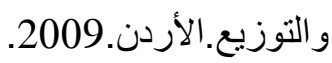
6-جابر عوض سيد حسن.العمل مع الجماعات أسس ونماذج نظرية.المكتب الجامعي الحديث.

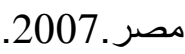


7- جيري ل جيري.ترجمة وليد عبد اللطيف هو انة.معهد الإدارة العامة.السعودية.1988.

8- حسان الجيلاني.التنظيم و الجماعات.دار الفجر للنشر و التوزيع.مصر .2008.

9- حسين حريم.السلوك التنظيمي المعاصر .كلية التجارة الإسكندرية.مصر .2003.

10- الحميد عطية.طريقة العمل مع الجماعات أساسيات و مفاهيم الممارسة.الدار الجامعية

للنشر و التوزيع.مصر .2004.

11- شبد منور عبودي.التغيير والتطوير,ط1.دار كنوز المعرفة للنشر

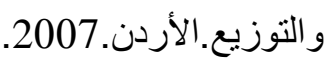

12- صلاح الدين محمد عبد الباقي.السلوك التنظيمي.دار الجامعة الجديدة.مصر.2003.

13- العايب رابح.مدخل إلى علم النفس العمل و التنظي.دار الهدى للنشر و التوزيع.عين مليلة.

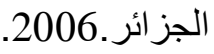

14- العامري والفوزان.مقاومة الموظفين للتغيير في الأجهزة الحكومية بالسعودية أسبابها وعلاجها.مجلة الإدارة العامة. المجلد/37.العدد/3.

15- عدنان أبو مصلح.معجم علم الاجتماع.دار أسامة للنشر و التوزيع.الأردن.2006. 16- لوكيا الهاثشي.السلوك التنظيمي.دار الهدى للنشر و التوزيع. عين مليلة. الجزائر.2006. 17- لوكيا الهاثمي وجابر نصر الدين. مفاهيم أساسية في علم النفس الاجتماعي. دار الهدى للنشر و التوزيع. عين مليلة .الجز ائر .2006. 18- المرسي و جمال الدين.الثقافة التنظيمية و التغيير .الدار الجامعية.مصر .ب ت. 19- موريس أنجرس.ترجمة بوزيد صحراوي.منهجية البحث العلمي في العلوم الإنسانية. دار القصبة للنشر و التوزيع.الجز ائر.2006.

20-Roger Mucchielli. La dynamique des groupes.eds.esf.France.1977.

21-Fulmer Robert M. The new management.4 ed.Mac Milan publishing Co.New York.USA.1989.

22- Laurence Siegel and Irving. Personnel and organizational psychology. Library of congress.usa.1982.

23-Brown $d$ and Harvey d.an expérience approach to organizational development.7 ed.prentice-hall New Jersey.USA.2006. 